\title{
Psychosocial perspectives in the treatment of pediatric chronic pain
}

Bryan D Carter ${ }^{1 *}$ and Brooke M Threlkeld ${ }^{1,2}$

\begin{abstract}
Chronic pain in children and adolescents is associated with major disruption to developmental experiences crucial to personal adjustment, quality of life, academic, vocational and social success. Caring for these patients involves understanding cognitive, affective, social and family dynamic factors associated with persistent pain syndromes. Evaluation and treatment necessitate a comprehensive multimodal approach including psychological and behavioral interventions that maximize return to more developmentally appropriate physical, academic and social activities. This article will provide an overview of major psychosocial factors impacting on pediatric pain and disability, propose an explanatory model for conceptualizing the development and maintenance of pain and functional disability in medically difficult-to-explain pain syndromes, and review representative evidence-based cognitive behavioral and systemic treatment approaches for improving functioning in this pediatric population.
\end{abstract}

Keywords: Chronic pain, Children, Adolescents, Psychosocial, Cognitive behavioral therapy

\section{Review}

\section{Background}

It has been estimated that fifteen to thirty percent of children and adolescents experience chronic pain, with prevalence increasing with age and occurring slightly more commonly in girls than boys $[1,2]$. Pain is considered a chronic condition when it has persisted for at least three months, moving beyond simple tissue damage (nociceptive) to subsequent changes within the peripheral and central nervous systems (neuropathic). The experience of chronic pain is also impacted by psychosocial factors (stress, negative affective states, family response, etc.) in addition to these biological factors [3]. The most commonly reported locations of pain in children and adolescents are the head, stomach, arms and legs. The most common chronic pain conditions in children include migraine, recurrent abdominal pain, and general musculoskeletal pain [2]. Symptoms of pediatric chronic pain can be severe and disabling, impairing the daily functioning of children and having an adverse impact on their families. Therefore, it is paramount that these chronic conditions

\footnotetext{
* Correspondence: bdcart01@louisville.edu

'Division of Child, Adolescent \& Family Psychiatry, University of Louisville School of Medicine, Bingham Clinic, 200 East Chestnut Street, Louisville, KY 40202, USA

Full list of author information is available at the end of the article
}

be accurately assessed and treated in order to improve functioning and prevent long-term sequelae and deviation from a normal developmental trajectory $[3,4]$.

There are a wide variety of medically difficult-toexplain chronic painful conditions that present in the pediatric population, which are often referred to as medically unexplained syndromes (MUS) [5]. These include such conditions as juvenile fibromyalgia syndrome (JFMS), chronic fatigue syndrome (CFS), widespread pain syndrome (WPS), chronic pelvic pain, irritable bowel syndrome (IBS), recurrent abdominal pain (RAP), tension headaches, noncardiac chest pain, complex regional pain syndrome (CRPS), reflex sympathetic dystrophy (RSD), and postural orthostatic tachycardia syndrome (POTS), among others. Central to these conditions is a wide discrepancy in the actual tissue damage sustained by a patient, the perceived severity of the condition, and the degree of disability exhibited. Alternatively, patients with more clearly delineated medical disorders, e.g., childhood leukemias (e.g., ALL, AML), juvenile rheumatoid arthritis (JRA), sickle cell disease (SCD), systemic lupus erythematosus (SLE), to mention some of the major illnesses, often experience limitations in their daily functioning due to the effects of debilitating pain and accompanying fatigue and/or the side effects of treatment. Lastly, there are those painful 
pediatric conditions which do not fall neatly on either end of the continuum with regard to how well an organic explanation fits the patient's reported level of pain or disability, e.g., certain headache variants, costochondritis, Ehlers-Danlos syndrome, Tietze syndrome, to give some examples (see Figure 1). The current review will focus primarily on psychosocial approaches to the treatment of the medically difficult-to-explain chronic painful conditions.

In medically unexplained pain syndromes (MUS) it has been suggested that the pain, fatigue, and functional limitations associated with these conditions may be due, at least in part, to abnormalities in centrallymediated processing functions rather than damage or inflammation of peripheral structures [5]. Neuroanatomically, the hypothalamic-pituitary-adrenal (HPA) axis is often implicated in this process. This dysregulation, which may be triggered by infection, injury or intense physical or psychological stress, results in a malfunction of the central mechanisms that regulate pain, energy, sleep, concentration, memory, etc. [6]. More specifically, increased neural activity in the posterior insula region of the brain has been implicated as at least a component of the sensory amplification seen in these patients [7]. Other central nervous system mechanisms that may be involved in the generation and maintenance of chronic pain include loss of descending analgesic activity and central sensitization, diminished activity of the descending serotonergic-noradrenergic system, and increased activity of endogenous opioidergic systems [7]. Behaviorally, evidence suggests that pain and fatigue can become classically conditioned to (associated with) certain stimuli in the environment, resulting in functional limitations when the individual is confronted with these stimuli. A number of functional imaging studies have demonstrated increased neural activity in brain structures involved in the processing of sensation, movement, cognition and emotion in patients with these conditions, as compared to healthy controls experiencing the same stimuli [8].
Patients with these conditions often experience considerable skepticism and avoidance by health care providers due, in part, to the difficulty in assigning an accurate diagnosis. On the other hand, for the treating physician the patient's clinical presentation may be frustrating due to the absence of a clear cut etiological explanation, inconclusive investigative tests, and lack of well validated medical treatments. This can lead the physician to ascribe the patient's symptoms primarily to psychological factors. However, referral to a child psychologist or psychiatrist is often met with defensiveness and even anger on the part of the patient and/or family, who continue to place a high value on finding a specific and readily remediable physical explanation. In such circumstances the patient continues to experience a lowered quality of life with reduced functioning in multiple arenas critical to optimal development. This prolonged frustration of seeking a clear medical explanation and treatment approach may further contribute to symptom exacerbation and feelings of hopelessness. This can set into motion an increased interdependency on parents and caregivers and reduced demands on the patient, that may establish a level of adaptation below the patient's premorbid baseline level. Secondary gain associated with the sick role and reduced physical activity leading to deconditioning produces further disability [9].

\section{Psychosocial factors in pediatric pain}

A biopsychosocial conceptualization of chronic pain posits a conceptual shift away from attempting to differentiate physical from mental or emotional pain. This model acknowledges the multidimensional nature of pain in which biological, psychological, individual, social and environmental variables are interactive in the development, maintenance, and subjective experience of pain and disability [10-15].

A proposed dynamic-interactive explanatory model underlying this process is presented in Figure 2. This model postulates that individuals who develop these

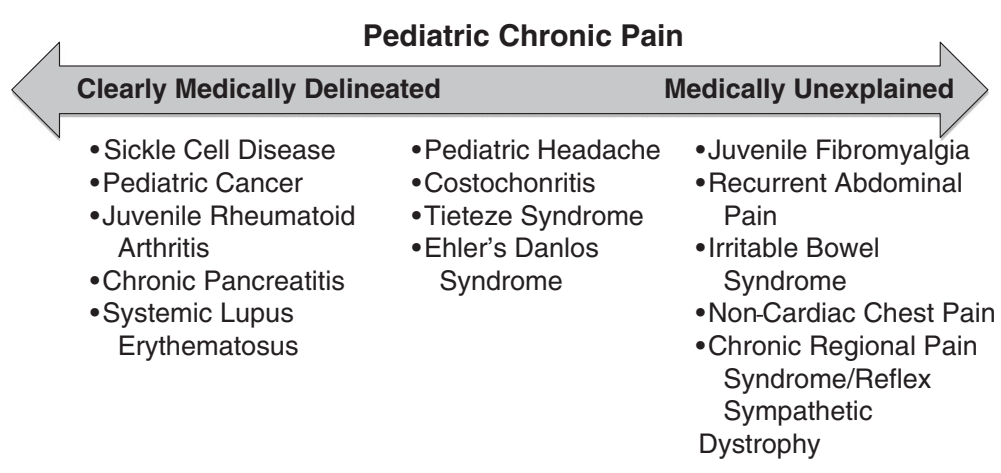

Figure 1 Continuum of painful conditions. 


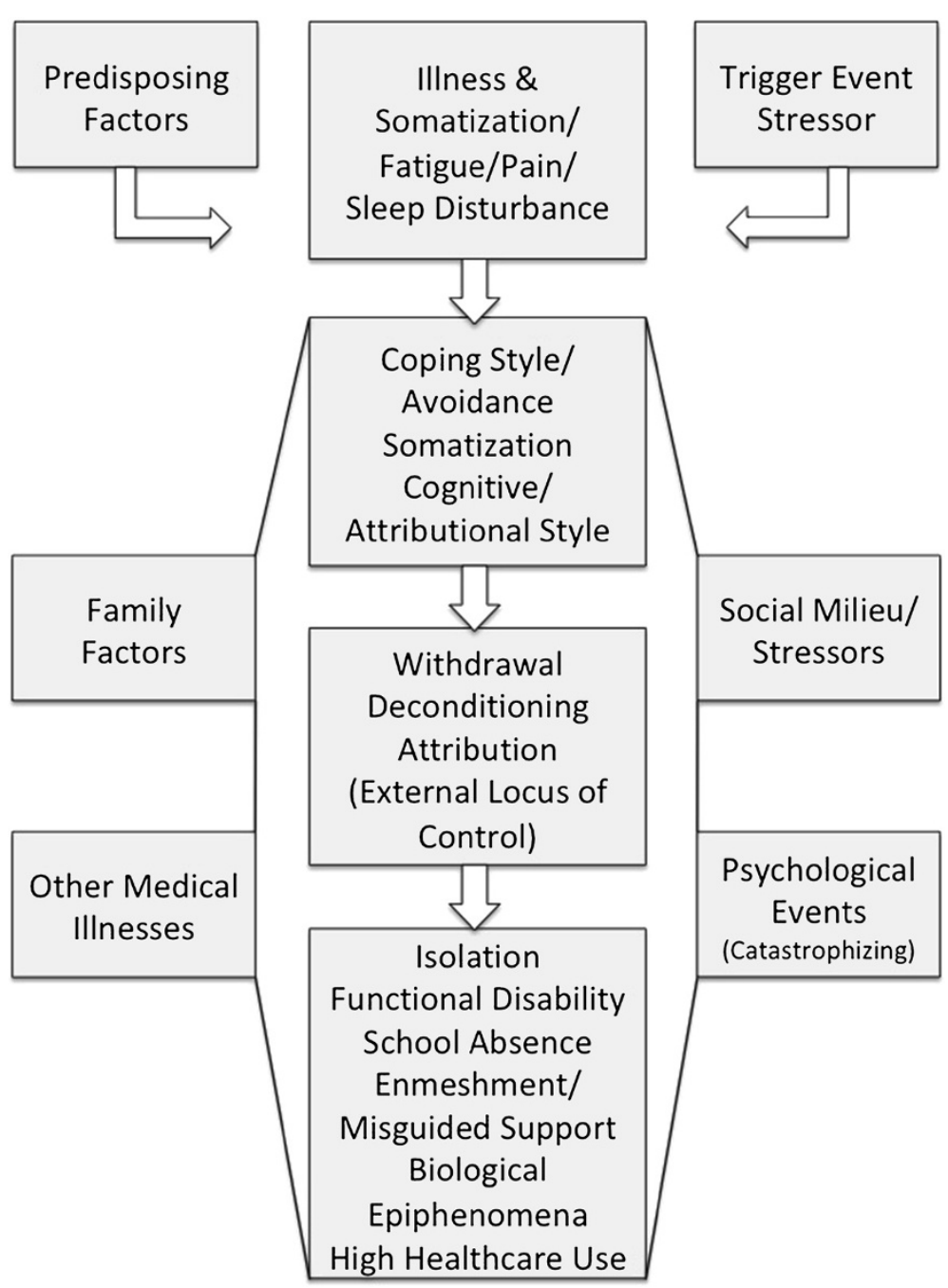

Figure 2 Explanatory model of chronic pain.

conditions may have Predisposing Factors or vulnerabilities which, when combined with overt or covert Trigger Events (viral illness, psychological stress), result in an initial Illness with associated Somatic Symptoms including Pain and/or Fatigue and Sleep Disturbance. This may lead to the patient engaging in Avoidance of activity as a primary Coping Style, Somatization (increased vigilance to physical symptoms) and Attribution of the illness primarily toward events outside their control, i.e., External Locus of Control. Influenced by additional events such as Family Factors (overprotection, triangulation), Social Milieu and Stressor factors (peer relationship issues), Other Medical Illness (low grade infections, pain/fatigue exacerbations), and Psychological Events (catastrophizing cognitions), the patient may engage in further Withdrawal, leading to Deconditioning and snowballing Increasing Attributions that their illness/ debilitation is due solely to a unitary disease process for which there is a unitary passive treatment (medication, surgery, etc.). The final pathological outcome is a patient who experiences increasing social Isolation, increased Functional Disability, Enmeshment with their primary caregivers, and additional Biological Epiphenomena and High Healthcare Use that further reinforce a somatic focus and an emphasis on finding a unitary medical "cure." The following section will address the findings of investigations supporting components of this explanatory model.

\section{Family factors}

Chronic pain has an adverse impact on the overall quality of life for both the child and the family [16], leading many to endorse a stress appraisal and coping model in which child disability and family dynamics are a function of the 
child and family interpretation of symptoms, type of coping employed and parental supportive efforts $[9,14,17,18]$. For some families the child's pain symptoms may play a functional role within family interaction patterns and relationships [19-23]. More solicitous parental responses to pain behaviors (e.g., caregivers' sympathy, attention to symptoms, emotional reactions, modeling of symptoms, and reinforcement of pain behavior via avoidance of responsibilities) have been associated with greater pain, sick role behavior and functional disability, independent of stress level or pain intensity [24-34]. In a study of children with chronic functional abdominal pain, when parents attended to symptom complaints, their children exhibited nearly twice as many such complaints [35]. Table 1 gives examples of family dynamics that are frequently observed in patients with chronic pain.

\section{Coping, cognitive style and personality factors}

For children suffering from painful medical conditions, the level at which they are able to function is influenced by a number of individual and systemic factors including child and family interpretation of pain symptoms, type of coping employed, and parental attempts to support their child's efforts to cope with the pain $[15,17,18]$. Children with chronic pain have been found to possess too few and ineffective coping strategies and portray themselves as having a lack of control over many aspects of their symptoms $[36,37]$. Claar, Walker and Smith [38] found pain and functional disability to be more common in pediatric patients with lower perceived competence in academic, social and athletic arenas, and pain-related disability to be reinforced if it allowed the individual to avoid activities at which the child believes him/herself to be ineffective or unsuccessful. Additionally, these children exhibited a tendency towards

Table 1 Family Dynamics Interacting with Pain and Functioning

\begin{tabular}{ll}
\hline Family Dynamic & Description \\
\hline Overprotection & $\begin{array}{l}\text { Belief that restricting patient from activity is } \\
\text { needed for improvement in symptoms. }\end{array}$ \\
Misguided support & $\begin{array}{l}\text { Parental behaviors that either lower expectations } \\
\text { or apply excessive pressure for rapid change and } \\
\text { improvement in function. }\end{array}$ \\
$\begin{array}{l}\text { Dysfunctional } \\
\text { Communication }\end{array}$ & $\begin{array}{l}\text { Poor conflict resolution, difficulty communicating } \\
\text { charged issues. }\end{array}$ \\
Patterns & $\begin{array}{l}\text { Patient and family attribute both illness and } \\
\text { recovery solely to factors outside themselves and } \\
\text { often beyond their control. }\end{array}$ \\
Dependions & $\begin{array}{l}\text { Loss of self-confidence due to family members } \\
\text { increasingly taking over patient responsibilities and } \\
\text { providing assistance that may not necessarily } \\
\text { be needed. }\end{array}$ \\
Social Isolation & $\begin{array}{l}\text { Patient becomes anxious and avoidant } \\
\text { of normal peer situations. }\end{array}$ \\
\hline
\end{tabular}

perfectionism and setting exceedingly high expectations [38]. In contrast, children who employ more active coping strategies report a greater sense of control and display less pain behavior, social withdrawal and functional disability $[39,40]$. Negative emotions (anxiety, depression) and poor emotional regulation have been found to be associated with greater functional disability [7,41-44]. Furthermore, regardless of the perceived pain severity, when children regard their pain to be a serious health-threatening condition and their coping ability to be low, their pain tolerance is lower.

Children with chronic pain have been observed to report greater pain behavior if they exhibit a cognitive pattern of "catastrophizing," i.e., a cognitive style characterized by increased focusing on pain and exaggerated/fearful appraisals of pain symptoms and their consequences. This cognitive style is associated with increased pain severity, lower pain tolerance, greater functional disability, more anxiety and depression, and increased use of analgesics $[45,46]$. The presence of learning disabilities, unrealistic goals in a high-achieving perfectionistic child, early pain experiences, a passive or dependent coping style, marital problems in the home, and chronic illness in a parent have been shown to be associated with visceral pain-associated disability [47]. Clinically, patients experiencing significant functional disability associated with pain have been found to manifest some of the following qualities: extreme conscientiousness, obsessiveness, sensitivity and insecurity; anxious with a tendency to set high standards of achievement resulting in placing considerable stress on themselves; family members who may tend to impose high academic and behavioral standards $[11,48]$.

\section{Sleep}

Sleep disturbance is prominent in pediatric patients with chronic conditions, particularly when pain is involved [49-55]. As a result, resolution of sleep disturbances plays an important role in the recovery process [50]. The relationship between pain and sleep is bidirectional, i.e., insufficient or disrupted sleep may increase the level of pain experienced and chronic pain increases the likelihood of sleep disruption [56]. While the mechanism responsible for this relationship is not clearly understood, it may be due to a disrupting effect on emotional regulation, attention and behavioral control which impairs the teen's ability to distract themselves from the pain sensations [56], or to neurophysiological changes that increase pain sensitivity $[57,58]$. Disturbances in sleep in children have been shown to be a major contributor to increased pain intensity, decreased health-related quality of life, and decreased functioning $[51,52,59]$.

\section{Psychosocial treatment components and approaches}

Psychosocial treatments for chronic pediatric pain attempt to address both symptom reduction and management as 
well as reduce functional disability and improve quality of life. Such interventions are most effective when employed as part of a multidisciplinary and interprofessional team approach that encourages and facilitates open communication between all health care providers and educators, including the primary care physician, medical specialists, physical therapists, teachers, counselors, etc., in order to orchestrate a return to more normal and developmentally appropriate activities. One or more of these specific components may be needed in combination with pharmacological and physical exercise/therapy interventions. The particular individualized approach employed will vary dependent upon such factors as patient history and symptom presentation, response to previous treatments, unique family dynamics, and environmental factors (service availability, insurance coverage, etc.). Such a comprehensive multidisciplinary approach should be strongly considered when symptoms have become protracted and interfere in a major way with the patient's ability to function academically, socially or vocationally. The following is a review of specific psychosocial intervention components that have been developed and applied to these conditions. These have applicability to both child and adolescent patient populations.

\section{Cognitive behavioral therapy (CBT)}

$\mathrm{CBT}$ is the most well validated non-pharmacological treatment for chronic pain in pediatric patients [60]. One of the primary goals of CBT is to identify and correct cognitive distortions, which, in the case of chronic pediatric pain, may involve patient and parental beliefs about the child's illness and such factors as activity restriction, illness exacerbation, school attendance and social involvement, etc., that may impede movement towards rehabilitation. CBT approaches to pediatric pain have been shown to alter patient symptom-related beliefs (attributions) and, subsequently, level of functional disability [61]. Since it has been demonstrated that negative affective states are associated with pain perception and level of functional impairment [42], CBT interventions have also targeted reductions in anxiety, depressive and somatic symptoms. In particular catastrophic thinking, a prime target of CBT interventions, has been associated with poorer outcome and greater functional disability in patients with chronic pain. Some of the major cognitive distortions targeted in treating chronic pediatric pain from a CBT approach are described in Table 2. When delivered in a family-based treatment approach, CBT targets parental responses to the child's pain behaviors, leading to a decrease in reinforcement of these behaviors and increased reinforcement of improved child functioning. Several recent outcome studies of psychosocial interventions with
Table 2 Illness-Related Cognitive Distortions Targeted in Cognitive Behavioral Therapy

\begin{tabular}{ll}
\hline Child Cognitive Distortions & Parent Cognitive Distortions \\
\hline $\begin{array}{l}\text { Belief that one must } \\
\text { restrict activity and }\end{array}$ & $\begin{array}{l}\text { Hesitation to } \\
\text { involvement until } \\
\text { symptoms resolve }\end{array}$ \\
$\begin{array}{l}\text { Self-image and confidence } \\
\text { in interpersonal }\end{array}$ & Fear of worsening patient \\
relationships & symptoms by encouraging \\
$\begin{array}{l}\text { Acceptability of assertive } \\
\text { communication } \\
\text { and behavior }\end{array}$ & $\begin{array}{l}\text { Fear of teen relapse leading to } \\
\text { overprotection and } \\
\text { overreaction to even } \\
\text { Over-emphasis on peer acceptance } \\
\text { and "pleasing others" }\end{array}$ \\
$\begin{array}{l}\text { Over-dependence on others in order } \\
\text { to recover from illness }\end{array}$ & $\begin{array}{l}\text { Belief that patient is "faking" } \\
\text { or exaggerating symptoms }\end{array}$ \\
\end{tabular}

Setting realistic standards for achievement and success

Overcoming feelings of invalidation

Pessimism regarding future health outcome and personal success

pediatric chronic pain, most involving a strong CBT component, are summarized in Table 3.

In a study of thirty adolescents with JFMS randomly assigned to 8 weeks of either CBT or self-monitoring, those receiving CBT demonstrated significantly greater ability to cope with pain than those in the selfmonitoring only condition [62]. On follow up, subjects had significantly lower levels of functional disability and depressive symptoms compared to baseline, but those who received self-monitoring followed by CBT received the most benefit.

Kashikar-Zuck and colleagues [63] investigated the efficacy of a CBT intervention compared with a fibromyalgia educational (FE) program, for reducing functional disability, pain, and depressive symptoms in 114 adolescents (aged 11 to 18 years) with fibromyalgia. Subjects received usual medical care for eight weeks, and then were randomized to eight weekly CBT or FE sessions with two "booster" sessions. Baseline, eighth week of treatment, and six-month follow-up outcome measures were obtained. The investigators found that almost $88 \%$ of participants completed the treatment protocol. Patients from both groups had significantly reduced functional disability, pain, and depressive symptoms. However, CBT was significantly better than FE for reducing functional disability. Both groups had a clinically significant reduction in depressive symptoms, and by the end of the study, the mean scores were in the nondepressed range. However, neither group attained a clinically significant reduction in pain. 
Table 3 Recent Intervention Studies for Pediatric Chronic Pain

\begin{tabular}{|c|c|c|c|c|}
\hline Authors (Year) & Condition (s) & Subjects & Modality & Outcome \\
\hline \multirow{2}{*}{$\begin{array}{l}\text { Kashikar-Zuck, Ting, Arnold, Bean, } \\
\text { Powers, Graham, Passo, Schikler, } \\
\text { Hashkes, Spalding, Lynch-Jordan, } \\
\text { Banez, Richards, \& Lovell (2011) }\end{array}$} & \multirow{2}{*}{$\begin{array}{l}\text { Juvenile } \\
\text { Fibromyalgia }\end{array}$} & 114 & \multirow{2}{*}{$\begin{array}{l}8 \text { weekly sessions of CBT } \\
\text { or FE (Fibromyalgia } \\
\text { Education) }+2 \text { "booster } \\
\text { sessions" }\end{array}$} & \multirow{2}{*}{$\begin{array}{l}\text { Significant reduction in functional } \\
\text { disability, pain and depressive } \\
\text { symptoms with CBT showing } \\
\text { significantly greater reduction in } \\
\text { functional disability }\end{array}$} \\
\hline & & $11-18$ year olds & & \\
\hline \multirow{2}{*}{$\begin{array}{l}\text { Robins, Smith, Glutting, } \\
\& \text { Bishop (2005) }\end{array}$} & \multirow{2}{*}{$\begin{array}{l}\text { Recurrent } \\
\text { abdominal pain }\end{array}$} & 69 & \multirow{2}{*}{$\begin{array}{l}\text { 5, } 40 \text { min sessions of CBT } \\
\text { family intervention with } \\
\text { standard medical care } \\
(n=40) \text { or standard medical } \\
\text { care alone }(n=29)\end{array}$} & \multirow{2}{*}{$\begin{array}{l}\text { CBT group reported significantly } \\
\text { reduced pain and fewer school } \\
\text { absences; no significant between group } \\
\text { differences in functional disability or } \\
\text { somatization }\end{array}$} \\
\hline & & $6-16$ year olds & & \\
\hline \multirow{2}{*}{$\begin{array}{l}\text { Palermo, Wilson, Peters, } \\
\text { Lewandowski, \& Somhegyi (2009) }\end{array}$} & \multirow{2}{*}{$\begin{array}{l}\text { Chronic } \\
\text { headache, } \\
\text { abdominal pain, or } \\
\text { musculoskeletal pain }\end{array}$} & 48 & \multirow{2}{*}{$\begin{array}{l}8 \text { week, internet-delivered } \\
\text { family CBT with sleep and } \\
\text { activity interventions and } \\
\text { wait-list control with } \\
\text { medical care only }\end{array}$} & \multirow{2}{*}{$\begin{array}{l}\text { CBT group significant reduction in } \\
\text { activity limitation and pain post } \\
\text {-treatment and } 3 \text {-month follow-up. No } \\
\text { group difference in depressive } \\
\text { symptoms or parental protectiveness. }\end{array}$} \\
\hline & & $11-17$ year olds & & \\
\hline \multirow{4}{*}{$\begin{array}{l}\text { Hechler, Blankenburg Dobe, } \\
\text { Kosfelder, Hubner \& Zernikow (2010) }\end{array}$} & \multirow{4}{*}{$\begin{array}{l}\text { Chronic, } \\
\text { debilitating pain not } \\
\text { responding to primary } \\
\text { care treatment }\end{array}$} & 33 & \multirow{4}{*}{$\begin{array}{l}3 \text { week, multimodal } \\
\text { inpatient pain treatment } \\
\text { including C BT (individual, } \\
\text { family, and group-based), } \\
\text { physical therapy, } \\
\text { art therapy, medications, and } \\
\text { academic support }\end{array}$} & \multirow{4}{*}{$\begin{array}{l}\text { Significant reduction in pain, disability, } \\
\text { school absence, and pain-related coping } \\
\text { maintained for } 12 \text { coping maintained } \\
\text { for } 12 \text { months post-treatment }\end{array}$} \\
\hline & & $7-10$ years olds and & & \\
\hline & & 167 & & \\
\hline & & $11-18$ years olds & & \\
\hline \multirow{2}{*}{$\begin{array}{l}\text { Vlieger, Menko-Frankenhuis, } \\
\text { Wolfkamp,Tromp \& Benninga (2007) }\end{array}$} & \multirow{2}{*}{$\begin{array}{l}\text { Functional } \\
\text { abdominal pain or } \\
\text { Irritable Bowel } \\
\text { Syndrome }\end{array}$} & 52 & \multirow{2}{*}{$\begin{array}{l}\text { 6, 50-min sessions of } \\
\text { Hypnotherapy }(n=27) \text { or } \\
\text { standard medical care with } \\
\text { attention/supportive } \\
\text { therapy control }(n=25)\end{array}$} & \multirow{2}{*}{$\begin{array}{l}\text { Hypnotherapy group reported a greater } \\
\text { significant reduction in pain diary } \\
\text { ratings of pain intensity and frequency }\end{array}$} \\
\hline & & 8-18 year olds & & \\
\hline \multirow{2}{*}{$\begin{array}{l}\text { Wicksell, Melin, Lekander } \\
\text { \& Olsson (2009) }\end{array}$} & \multirow{2}{*}{$\begin{array}{l}\text { Headache, } \\
\text { back/neck pain, } \\
\text { Complex Regional } \\
\text { Pain Syndrome, and } \\
\text { widespread musculoskeletal } \\
\text { pain }\end{array}$} & 18 & \multirow{2}{*}{$\begin{array}{l}10 \text { weekly sessions of ACT } \\
(n=18) \text { or } \\
\text { "Multidisciplinary } \\
\text { treatment" with } \\
\text { amitriptyline }(n=18)\end{array}$} & \multirow{2}{*}{$\begin{array}{l}\text { Greater improvement in ACT group as } \\
\text { evidenced by: decreased functional } \\
\text { disability, pain intensity, fear of re- } \\
\text { injury, and pain interference }\end{array}$} \\
\hline & & 10-18 year olds & & \\
\hline \multirow[t]{2}{*}{ Scharff, Marcus \& Masek (2002) } & \multirow[t]{2}{*}{ Migraine headache } & 36 & \multirow[b]{2}{*}{$\begin{array}{l}4,60 \text { min sessions of } \\
\text { biofeedback and stress } \\
\text { management training with } \\
\text { home practice }(n=13) \text { or } \\
\text { biofeedback placebo } \\
\text { control }(n=11) \text { or waitlist } \\
\text { control }(n=12)\end{array}$} & \multirow{2}{*}{$\begin{array}{l}\text { Biofeedback and stress management } \\
\text { group self reported greater post } \\
\text { treatment reduction in migraine pain }\end{array}$} \\
\hline & & 7-17 year olds & & \\
\hline
\end{tabular}




\section{Acceptance and commitment therapy (ACT)}

ACT, is a specific cognitive behavioral approach targeting belief systems in patients suffering from chronic and recurrent painful conditions, has been found to be beneficial for improving perceived functional ability, pain intensity, fear of re-injury, pain interference, and general quality of life [64-66]. ACT differs from traditional CBT approaches to pain management in that the patient learns to accept pain and abandon a primary focus on alleviating pain and the related negative sensations and experiences with which it is associated. Instead the emphasis of treatment is on promoting engagement in meaningful and valued experiences and life involvements. This is accomplished via identifying and gradually exposing the child to valued activities such as attending school, participating in recreational activities and spending time with friends. Acceptance interventions utilize developmentally appropriate mindfulness exercises, which assist with accepting unpleasant internal experiences. Treatment may also involve cognitive externalizing interventions, e.g., characterizing painful sensations as a "pain monster," in order to separate the experience of pain as independent from one's global sense of self [67]. ACT appears to improve patient "willingness to function" in spite of pain, anxiety and the potential negative physical consequences of pain.

\section{Hypnosis}

Clinical hypnosis has a long history as a valuable treatment component with children with chronic pain $[68,69]$, with neuroimaging studies demonstrating its efficacy in activating brain functions known to be involved in the processing of the pain experience [70]. Such hypnotherapeutic interventions as visual imagery, hypnoanesthesia, distancing and distraction techniques, and reframing likely alter the child's experiencing and interpretation of the sensations associated with pain. A controlled clinical trial of hypnotherapy demonstrated efficacy over standard medical care with supportive therapy in reducing pain intensity and frequency in a group of 8 to 18 year olds with recurrent abdominal pain or irritable bowel syndrome [71].

\section{Graduated exercise and activity}

Increased physical activity and graduated exercise (GE) are a critical component to recovery from pediatric conditions involving functional disability and pain [72]. A decrease in expectations for physical activity and associated responsibility has been associated with less favorable five-year outcome in adolescents with chronic fatigue and pain [73], and adolescents with significant functional disability associated with their fatigue and pain have been found to have higher levels of parental restriction from activity than their peers with juvenile arthritis [74].

Graduated exercise serves to reverse the effects of physical deconditioning experienced by many children and initiates the process of "re-regulation," via desensitization of the fear of the physical consequences of overexertion and learning to tolerate temporary discomfort in exchange for later improvement. In addition, increased activity enhances self-confidence regarding one's ability to function physically and socially and serves to combat the forced dependency imposed by many conditions. Most GE interventions for chronic pain focus on stretching, mobility and aerobic tolerance [75]. Garralda and Chandler [76] have described GE combined with $\mathrm{CBT}$ as the most promising intervention for managing painful and fatiguing conditions in adolescents. GE has been included in a number of integrative treatment programs and is valuable in improving debilitating symptoms, sense of "wellness" and school attendance over supportive care alone [77].

\section{Improving academic attendance and functioning}

Pediatric pain typically has a significant negative impact on academic attendance and performance, though patients will vary in the level of social and academic impairment exhibited. In a study of 221 adolescents with chronic pain, subjects missed an average of 4.5 school days per month and almost half reported a decrease in grades since the onset of their pain condition [78]. Long-term follow-up studies have shown that poorer academic performance and attendance can have lasting negative consequences on an adolescent's engagement in college-level higher education and employment [79].

Active efforts at school reintegration should be a central component in the treatment of pediatric chronic pain. School systems vary widely in their receptiveness to recommended accommodations and interventions. Therefore, it is important to become familiar with the appropriate federal and state regulations and statutes that apply to pediatric pain conditions, such as the Individuals with Disabilities Education Act (IDEA) and Section 504 of the Rehabilitation Act and the Americans with Disabilities Act, which require accommodations and modifications be made so that the student can fully participate in the classroom and maximally benefit from educational instruction.

\section{Sleep intervention}

Resolution of sleep disturbances plays an important role in the treatment of chronic pediatric pain. Sleep disturbance alone predicts lower health-related quality of life and higher functional disability in children and adolescents with chronic pain [80]. For example, compared to a no-treatment control group, pediatric patients 
receiving sleep hygiene education reported a reduction in frequency and duration of migraine headache [81]. Cognitive-behavioral interventions for sleep have also been shown to improve symptoms and quality of life in adolescents with juvenile fibromyalgia [50]. Intervention for sleep involves identifying poor sleep hygiene patterns and implementing strategies to improve sleep regulation. Such strategies include: establishing a regular bedtime routine and sleep schedule, eliminating or limiting daytime naps, limiting caffeine intake, increasing morning sun exposure, discontinuing potentially stimulating activities such as television/computer/video games, etc., within $30 \mathrm{~min}$ of bedtime, establishing a healthy morning exercise routine, altering sleep environment to be a cool, dark, quiet and relaxing space that is used exclusively for sleep. Weekly sleep logs are often utilized to record gradual shifts in sleep patterns and to monitor and encourage improved sleep hygiene and quality.

\section{Integrated approaches}

In a meta-analytic review of twenty-five psychological intervention trials with children and adolescents with chronic pain, Palermo and colleagues [82] found a large positive effect of psychological intervention on pain reduction at immediate post-treatment and follow-up. These studies included youth with headache, abdominal pain and fibromyalgia. Less robust effects were found for improvements in disability and emotional functioning. CBT, relaxation training, and clinical biofeedback all produced significant pain reduction, and this was true for self-administered as well as therapist-administered interventions.
A number of treatment studies have integrated a combination of interventions that include CBT, behavioral, family-systems and GE components. The STAIRway to Health program (Structured Tailored Incremental Rehabilitation) incorporates several aspects of previously researched approaches [75]. Patients and parents are educated in a holistic understanding of their illness that discourages an exclusively physical or psychological approach to understanding the illness. Educational components include explaining vicious cycles that exacerbate illness, including those of nutrition, sleep patterns, physical deconditioning, social isolation, educational estrangement, and emotional cycles (including loss of self-esteem and confidence), as well as bolstering adaptive coping strategies and re-evaluating negative attributions about the prognosis of their illness and the future. A tailored gradual return to school is planned, as well as a gradual return to normal social activity. Though sample size was somewhat small, compared to a control "pacing program" group, the adolescents in the STAIRway group demonstrated significant improvements in school attendance, activity scores, and global health ratings by both the teen and treating clinician. Contrary to common patient and parental precautions to refrain from more vigorous and sustained physical activity, closely monitored active rehabilitation did not exacerbate symptoms in subjects [75].

\section{Children's health and illness recovery program (CHIRP)}

The Children's Health and Illness Recovery Program (CHIRP) is a comprehensive, multimodal outpatient intervention designed for adolescents with chronic

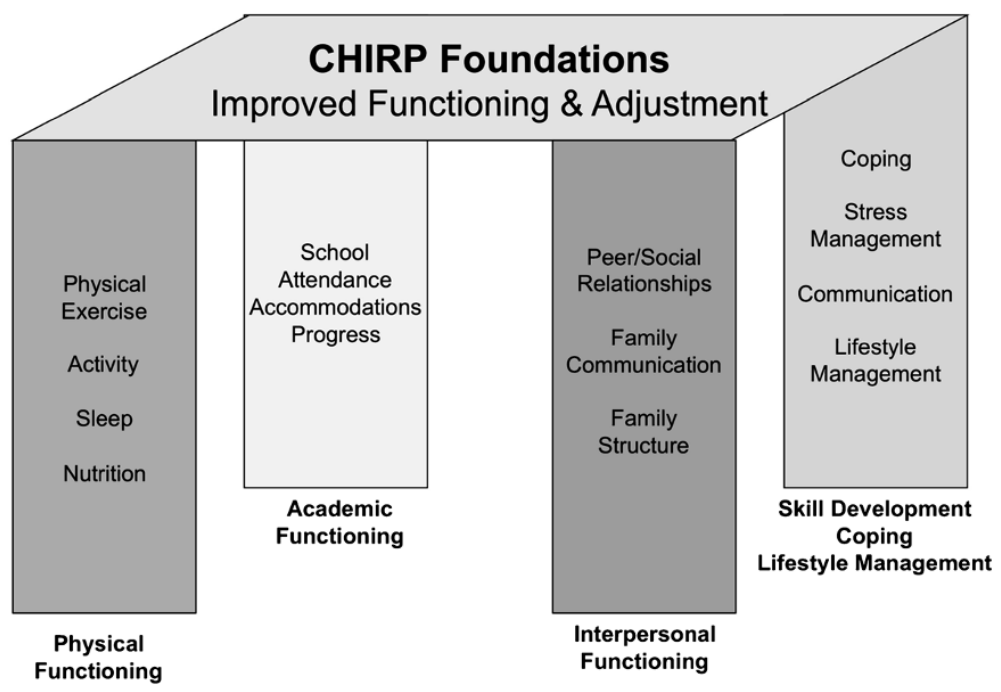

Figure 3 CHIRP treatment model. 
painful and fatiguing conditions (Carter, Kronenberger, Bowersox, Hartley, Sherman: Children's health and illness recovery program clinician's handbook, unpublished). CHIRP employs a 12-session manualized treatment protocol integrating many validated treatment components in a workbook format, including familybased CBT. CHIRP activities are designed to assist patients in multiple areas including: 1) medical treatment adherence and related lifestyle modifications, 2) identifying and managing stress, 3) improving active coping, time management and problem-solving skills, 4) improving assertive communication and interpersonal relationships, 5) utilizing relaxation and self-soothing behaviors, 6) enhancing functional independence and communication in the context of the patient's family, and 7) advocating for appropriate educational accommodations. The CHIRP model (see Figure 3) encourages regular communication among patient, family, health care providers and school officials, to facilitate return to school and more normal social functioning. Preliminary clinical outcome data on subjects who completed all sessions demonstrated significant parent- and patientbased ratings of improvement in functioning and reduced pain and fatigue in adolescents with painful and fatiguing illnesses [83].

\section{Inpatient treatment for pediatric chronic pain}

Multidisciplinary inpatient treatment programs designed to initiate more typical childhood functioning in patients with chronic pain may be indicated for more severe cases that are non-responsive to outpatient interventions. A study of 200 children and adolescents with chronic pain demonstrated the benefits of inpatient multimodal treatment [84]. A multidisciplinary team of pediatricians, clinical psychologists, psychiatrists, nurses, physiotherapists, occupational therapists, and social workers conducted the three-week inpatient treatment. Behavioral health treatment consisted of individual, family, and group therapy sessions incorporating cognitive behavioral principles and trauma-specific interventions. Adjunctive physical therapy, art therapy and medications were also provided. Participants received educational services during the day to promote school reintegration. Three-month and 12-month post-treatment assessment revealed a significant decline in pain intensity, painrelated disability, school absence, and pain-related coping. Participants reported a $60 \%$ reduction in use of analgesics at one-year post treatment [84]. The rarity and high cost of such programs reduces accessibility for most patients and may not be appropriate for those who are less impaired and higher functioning. Multimodal outpatient treatment options may be more suitable for these children.

\section{Conclusions}

Comprehensive treatments for pediatric chronic pain need to include attention to psychosocial factors that are associated with and perpetuate symptom persistence and contribute to functional morbidity. There is a growing body of evidence-based literature supporting interventions based upon cognitive, behavioral, family- and social-systems models in improving patient symptoms, quality of life and overall functioning. Future studies need to further investigate these treatments compared to more standard medical interventions alone, as well as efforts to make these interventions more accessible via such mechanisms as digital and web-based tools [85].

\section{Abbreviations}

JFMS: juvenile fibromyalgia syndrome; CFS: chronic fatigue syndrome; WPS: widespread pain syndrome; IBS: irritable bowel syndrome;

RAP: recurrent abdominal pain; CRPS: complex regional pain syndrome; RSD: reflex sympathetic dystrophy; POTS: postural orthostatic tachycardia syndrome; ALL: acute lymphocytic leukemia; AML: acute myeloid leukemia; JRA: juvenile rheumatoid arthritis; SCD: sickle cell disease; SLE: systemic lupus erythematosus; MUS: medically unexplained pain syndromes;

HPA: hypothalamic-pituitary-adrenal; PADS: pain-associated disability syndrome; CBT: cognitive-behavioral therapy; FE: fibromyalgia educational; ACT: acceptance and commitment therapy; GE: graduated exercise; IDEA: Individuals with Disabilities Education Act; STAIRway: Structured Tailored Incremental Rehabilitation; CHIRP: Children's Health and IIIness Recovery Program.

\section{Competing interests}

The authors declare that they have no competing interests.

\section{Acknowledgements}

Dr. Carter's research on CHIRP was supported by Grants Number \#28-9 and \#2011-7, titled, "Characterization and Treatment of Adolescents with Fatiguing and Painful Medical Conditions as seen in CHIRP (Children's Health \& Illness Recovery Program)" (Bryan D. Carter, Ph.D., PI) from the James R. Petersdorf Fund of Norton Healthcare, Inc.

\section{Author details}

'Division of Child, Adolescent \& Family Psychiatry, University of Louisville School of Medicine, Bingham Clinic, 200 East Chestnut Street, Louisville, KY 40202, USA. ${ }^{2}$ Spalding University, 845 South 3rd Street, Louisville, KY 40203, USA.

\section{Authors' contributions}

BC literature review and manuscript preparation. BT literature review and manuscript preparation. Both authors read and approved the final manuscript.

Received: 8 March 2012 Accepted: 7 June 2012

Published: 7 June 2012

\section{References}

1. Perquin CW, Hazebroek-Kampschreur AJM, Hunfeld JAM, Nohnen AM, van Suijlekom-Smit LWA, Passchier J, van der Wouden JC: Pain in children and adolescents: a common experience. Pain 2000, 87:51-58.

2. Huguet A, Miro J: The severity of chronic pediatric pain: an epidemiological study. J Pain 2008, 9(3):226-236.

3. Leo RJ, Srinivasan SP, Parekh S: The role of the mental health practitioner in the assessment and treatment of child and adolescent chronic pain. Child Adolesc Ment Health 2011, 16(1):2-8.

4. Jones JF, Nisenbaum R, Solomon L, Reyes M, Reeves WC: Chronic fatigue syndrome and other fatiguing illnesses in adolescents: a populationbased study. J Adolesc Health 2006, 35:34-40.

5. Johnson SK: Medically unexplained illness: gender and biopsychosocial implications. Washington DC: American Psychological Association; 2007. 
6. Gaab J, Huster D, Peisen R, Engert V, Heitz V, Schad T, Schurmeyer TH, Ehlert $U$ : Hypothalamic-pituitary-adrenal axis reactivity in chronic fatigue syndrome and health under psychological, physiological, and pharamacological stimulation. Psychosom Med 2002, 64(6):951-962.

7. Lee YC, Nassikas NJ, Clauw DJ: The role of the central nervous system in the generation and maintenance of chronic pain in rheumatoid arthritis, osteoarthritis and fibromyalgia. Arthritis Res Ther 2011, 13:211.

8. Apkarian AV, Thomas PS, Krauss BR, Szevernyi NM: Prefrontal cortical hyperactivity in patients with sympathetically mediated chronic pain. Neurosci Lett 2001, 311(3):193-197.

9. Stang PE, Osterhaus JT: Impact of migraine in the United States: data from the National Health Interview Survey. Headache 1993, 33(1):29-35.

10. American Pain Society: Pediatric chronic pain: a position statement from the American Pain Society. Am Pain Society Bull 2001, 11(1):10-12.

11. Bursch $B$, Joseph $M H$, Zeltzer LK: Pain-associated disability syndrome. In Pain in Infants, Children, and Adolescents. Edited by Schechter NL, Berde CB, Yaster M. Philadelphia: Lippincott: Williams, \& Williams; 2003:841-848.

12. Zeltzer $L$, Bursch $B$, Walco $G$ : Pain responsiveness and chronic pain: a psychobiological perspective. J Dev Behav Pediatr 1997, 18(6):413-422.

13. Hyams JS, Hyman PE: Recurrent abdominal pain and the biopsychosocial model of medical practice. J Pediatr 1998, 133(4):473-478.

14. Bursch B, Walco GA, Zeltzer L: Clinical assessment and management of chronic pain and pain associated disability syndrome. J Dev Behav Pediatr 1998, 19:45-53.

15. Zeltzer LK, Tsao JC, Bursch B, Myers CD: Introduction to the special issues on pain: from pain to pain-associated disability syndrome. $J$ Pediatr Psychol 2006, 31(7):661-666.

16. Hunfeld JAM, Perquin CW, Duivenvoorden HJ, Hazebroek-Kampschreur AA, Passchler J, van Suijlekom-Smit LWA, van der Wouden JC: Chronic pain and its impact on quality of life in adolescents and their families. J Pediatr Psychol 2001, 26:145-153.

17. Folkman S, Lazarus RS, Gruen RJ, DeLongis A: Appraisal, coping, health status, and psychological symptoms. J Pers Soc Psychol 1986, 50(3):571-579.

18. Lipani TA, Walker LS: Children's appraisal and coping with pain: relations to maternal ratings of worry and restriction in family activities. $J$ Pediatr Psychol 2006, 31:667-673.

19. Covelman K, Scott S, Buchanan B, Rossman F: Pediatric pain control: a family systems model. In Advances in pain research and therapy. Edited by Tyler DC, Krane EJ. New York: Raven; 1990:225-236.

20. Kopp M, Richter R, Rainer J, Kopp-Wilfling P, Rumpold G, Walter MH: Differences in family functioning between patients with chronic headache and patients with chronic low back pain. Pain 1995, 63:219-224.

21. Logan DE, Scharff L: Relationships between family and parent characteristics and functional abilities in children with recurrent pain syndromes: an investigation of moderating effects on the pathway from pain to disability. J Pediatr Psychol 2005, 30(8):698-707.

22. Naidoo P, Pillay YG: Correlations among general stress, family environment, psychological distress, and pain experience. Percept Mot Skills 1994, 78:1291-1296.

23. Scharff L, Langan N, Rotter N, Scott-Sutherland J, Schenck C, Tayor N, et al: Psychological, behavioral, and family characteristics of pediatric patients with chronic pain. Clin J Pain 2005, 21(5):432-438.

24. Fordyce WE: Behavioral methods for chronic pain and illness. St. Louis: Mosby; 1976.

25. Garber J, Zeman J, Walker LS: Recurrent abdominal pain in children: psychiatric diagnoses and parental psychopathology. J Am Acad Child Adolesc Psychiatry 1990, 29:648-656.

26. Gidron Y, McGrath PJ, Goodday R: The physical and psychosocial predictors of adolescents' recovery from oral surgery. J Behav Med 1995 18:385-399.

27. Liakopoulou-Kairis M, Alifieraki T, Protagora D, Kora T, Kondyli K, Dimosthenous $E$, et al: Recurrent abdominal pain and headache: psychopathology, life events and family functioning. Eur Child Adolesc Psychiatry 2002, 11:115-122.

28. Payne B, Norfleet M: Chronic pain and the family: a review. Pain 1986, 26(1):1-22

29. Schanberg LE, Anthony KK, Gil KM, Lefebvre JC, Kredich DW, Macharoni LM: Family pain history predicts child health status in children with chronic rheumatic disease. Pediatrics 2001, 108:E47.

30. Van Slyke DA, Walker LS: Mothers' responses to adolescent's pain. Clin J Pain 2006, 22(4):387-391.
31. Walker LS, Claar RL, Garber JL: Social consequences of children's pain: when do they encourage symptom maintenance? J Pediatr Psychol 2002, 27:689-698.

32. Walker LS, Garber J, Greene JW: Psychosocial correlates of recurrent childhood pain: a comparison of pediatric patients with recurrent abdominal pain, organic illness, and psychiatric disorders. J Abnorm Psychol 1993, 102:248-258.

33. Whitehead WE, Crowell MD, Heller BR, Robinson JC, Schuster MM, Horn S: Modeling and reinforcement of the sick role during childhood predicts adult illness behavior. Psychosom Med 1994, 56:541-550.

34. Walker LS, Zeman JL: Parental response to child illness behavior. J Pediatr Psychol 1992, 17:49-71.

35. Walker LS, Williams SE, Smith CA, Garber J, Van Slyke DA, Lipani TA: Parent attention versus distraction: impact on symptom complaints by children with and without chronic functional abdominal pain. Pain 2006, 122(1-2):43-52.

36. Branson SM, Craig KD: Children's spontaneous strategies for coping with pain. Can J Behav Sci 1988, 20:402-412.

37. Dunn-Geier BJ, McGrath PJ, Rourke BP, Latter J, D'Astous J: Adolescent chronic pain: the ability to cope. Pain 1986, 26:23-32.

38. Claar RL, Walker LS, Smith CA: Functional disability in adolescents and young adults with symptoms of irritable bowel syndrome: the role of academic, social, and athletic competence. J Pediatr Psychol 1999, 24(3):271-280.

39. Flor H, Birbaumer N, Rudy DC: The psychobiology of chronic pain. Adv in Behav Res and Therapy 1990, 12:47-84

40. Siegel $\amalg$, Smith KE: Children's strategies for coping with pain. Pediatrician 1989, 16(1-2):110-118.

41. Connelly M, Bromberg MH, Anthony KK, Gil KM, Franks L, Schanberg LE: Emotion regulation predicts pain and functioning in children with juvenile idiopathic arthritis: an electronic diary study. J Pediatr Psychol 2012, 37:43-52.

42. Gatchel R, Peng Y, Peters M, Fuchs P, Turk D: The biopsychosocial approach to chronic pain: scientific advances and further directions. Psychol Bull 2007, 133:581-624.

43. Kashikar-Zuck S, Goldschneider KR, Powers SW, Vaught MH, Hersey AD: Depression and functional disability in chronic pain. Clin J Pain 2001, 17:341-349.

44. Peterson CC, Palermo TM: Parental reinforcement of recurrent pain: the moderating impact of child depression and anxiety on functional disability. J Pediatr Psychol 2004, 29(5):331-341.

45. Crombez G, Bijttebier P, Eccleston C, Mascagni T, Mertens G, Goubert L, Verstraeten $\mathrm{K}$ : The child version of the pain catastrophizing scale (PCS-C): a preliminary validation. Pain 2003, 104:639-646.

46. Vervoort T, Goubert L, Eccleston C, Bijttebier P, Crombez G: Catastrophic thinking about pain is independently associated with pain severity, disability, and somatic complaints in school children and children with chronic pain. J Pediatr Psychol 2006, 31(7):674-683.

47. Hyman PE, Bursch B, Sood M, Schwankovsky L, Cocjin J, Zeltzer LK: Visceral pain-associated disability syndrome: a descriptive analysis. J Pediatr Gastroenterol Nutr 2002, 35:663-668.

48. Garralda M: Somatisation in children. J Child Psychol Psychiatry 1996, 37(1):13-33.

49. Aaltonen K, Hamalainen ML, Hoppu K: Migraine attacks and sleep in children. Cephalalgia 2000, 20:580-584.

50. Degotardi PJ, Klass ES, Rosenberg BS, Fox DG, Gallelli KA, Gottlieb BS: Development and evaluation of a cognitive-behavioral intervention for juvenile fibromyalgia. J Pediatr Psychol 2006, 31:714-723.

51. Huntley ED, Campo JV, Dahl RE, Lewin DS: Sleep characteristics of youth with functional abdominal pain and a healthy comparison group. $J$ Pediatr Psychol 2007, 32:938-949.

52. Long AC, Krishnamurphy V, Palermo TM: Sleep disturbances in school-age children and chronic pain. J Pediatr Psychol 2008, 33:258-268.

53. Meltzer LJ, Mindell JA, Logan DE: Sleep patterns in adolescent females with chronic musculoskeletal pain. Behav Sleep Med 2005, 3:305-314.

54. Miller VA, Palermo TM, Powers SW, Scher MS, Hershey AD: Migraine headaches and sleep disturbances in children. Headache 2003, 43:362-368.

55. Tsai SY, Labyk SE, Richardson LP, Lentz MJ, Brandt PA, Ward TM, et al: Brief report: actigraphic sleep and daytime naps in adolescent girls with chronic musculoskeletal pain. J Pediatr Psychol 2008, 33:307-311.

56. Lewin DS, Dahl RE: The importance of sleep in the management of pediatric pain. J Dev Behav Pediatrics 1999, 20:244-252. 
57. Lautenbacher S, Kundermann B, Krieg J: Sleep deprivation and pain perception. Sleep Med Rev 2006, 10:357-369.

58. Roehrs T, Hyde M, Blaisdell B, Greenwald M, Roth T: Sleep loss and REM sleep loss are hyperalgesic. Sleep 2006, 29:145-151.

59. Palermo TM, Kiska R: Subjective sleep disturbances in adolescents with chronic pain: relationship to daily functioning and quality of life. J Pain 2005, 6(3):201-207.

60. Christie D, Wilson C: CBT in paediatric and adolescent health settings: a review of practice-based evidence. Dev Neurorehab 2005, 8(4):241-247.

61. Jensen MP, Turner JA, Roman JM: Changing in beliefs, catastrophizing, and coping are associated with improvement in multidisciplinary pain treatment. J Consult Clin Psychol 2001, 69(4):665-662

62. Kashikar-Zuck S, Swain NF, Jones BA, Graham TB: Efficacy of cognitivebehavioral intervention for juvenile primary fibromyalgia syndrome. $J$ Rheumatol 2005, 32(8):594-602.

63. Kashikar-Zuck S, Ting TV, Arnold LM, Bean J, Powers SW, Graham TB, Passo MH, Schikler KN, Hashkes PJ, Spalding S, Lynch-Jordan AM, Banez G, Richards MM, Lovell DJ: A randomized clinical trial of cognitive behavioral therapy for the treatment of juvenile fibromyalgia. Arthritis Rheum 2012, 64(1):297-305

64. Wicksell RK, Dahl J, Magnusson B, Olsson GL: Using acceptance and commitment therapy in the rehabilitation of an adolescent female with chronic pain: a case example. Cogn Behav Pract 2005, 12:415-423.

65. Wicksell RK, Lennart M, Lekander M, Olsson GL: Evaluating the effectiveness of exposure and acceptance strategies to improve functioning and quality of life in longstanding pediatric pain - a randomized controlled trial. Pain 2009, 141:248-257.

66. Wicksell RK, Melin L, Olsson GL: Exposure and acceptance in the rehabilitation of adolescents with idiopathic chronic pain - a pilot study. Eur J Pain 2006, 11:267-274.

67. Wicksell RK, Greco LA: Acceptance and Commitment Therapy for Pediatric Chronic Pain. In Acceptance and mindfulness treatments for children and adolescents: A practitioner's guide. Edited by Greco LA, Hayes SC. Oakland, CA: New Harbinger Publications, Inc; 2008:89-113.

68. Evans S, Zelter LK: Complimentary and alternative approaches for chronic pain. In Pain in children: a practical guide for primary care. Edited by Walco GA, Goldschneider KR. Totowa, NJ: Humana Press; 2008:153-160.

69. Kohen DP, Olness K: Hypnosis and hypnotherapy with children. 4th edition. New York: Routledge; 2011.

70. Rainville P, Hofbauer RK, Bushnell MC, Duncan GH, Price DD: Hypnosis modulates activity in brain structures involved in the regulation of consciousness. J Cogn Neurosci 2002, 14:887-901.

71. Vlieger AM, Menko-Frankenhuis C, Wolfkamp SCS, Tromp E, Benninga MA: Hypnotherapy for children with functional abdominal pain or irritable bowel syndrome: a randomized controlled trial. Gastroenterology 2007, 133(5):1430-1436.

72. Anthony KK, Schanberg LE: Pediatric pain syndromes and management of pain in children and adolescents with rheumatic disease. Pediatr Clin of North Am 2005, 52(2):611-639.

73. Carter BD, Kronenberger WG, Edwards JF, Marshall GS, Schikler KN, Causey $\mathrm{DL}$ : Psychological symptoms in chronic fatigue and juvenile rheumatoid arthritis. Pediatrics 1999, 103(5):975-979.

74. Brace MJ, Smith MS, McCauley E, Sherry DD: Family reinforcement of illness behavior: a comparison of adolescents with chronic fatigue syndrome, juvenile arthritis, and healthy controls. J Dev Behav Pediatr 2000, 21:332-339.

75. Wright B, Ashby B, Beverley D, Calvert E, Jordan J, Miles J, Russell I, Williams C: A feasibility study comparing two treatment approaches for chronic fatigue syndrome in adolescents. Arch Dis Child 2005, 90:369-372.

76. Garralda $M$, Chandler T: Practitioner review: chronic fatigue syndrome in childhood. J Child Psychol Psychiatry 2005, 46(11):1143-1151.

77. Viner R, Gregorowski C, Wine M, Bladen D, Fisher M, Miller M, El Neil S: Outpatient rehabilitative treatment of chronic fatigue syndrome (CFS/ ME). Arch Dis Child 2004, 2004(89):615-619.

78. Logan DE, Simons LE, Stein MJ, Chastain L: School impairment in adolescents with chronic pain. J Pain 2008, 9(5):407-416.

79. Kashikar-Zuck S, Parkins IS, Ting TV, Verkamp E, Lynch-Jordan A, Passo M, Graham TB: Controlled follow-up study of physical and psychosocial functioning of adolescents with juvenile primary fibromyalgia syndrome. Rheumatol 2010, 49:2204-2209.
80. Long AC, Krishnamurthy $V$, Palermo TM: Sleep disturbances in school-age children with chronic pain. J Pediatr Psychol 2008, 33(3):258-268.

81. Bruni O, Galli F, Guidetti V: Sleep hygiene and migraine in children and adolescents. Cephalalgia 1999, 19(Suppl 25):57-59.

82. Palermo T, Eccleston C, Lewandowski AS, Williams A, Morley S: Randomized controlled trials of psychological therapies for management of chronic pain in children and adolescents: an updated meta-analytic review. Pain 2010, 148:387-397.

83. Carter BD, Kronenberger W, Sherman K, Threlkeld B: Clinical Outcomes of a Manualized Treatment for Adolescents with Chronic Pain and Fatigue. Paper presented at: The Society of Pediatric Psychology Midwest Regional Conference. Milwaukee; April 2012.

84. Hechler T, Blankenburg M, Dobe M, Kosfelder J, Hubner B, Zernikow B: Effectiveness of a multimodal inpatient treatment for pediatric chronic pain: a comparison between children and adolescents. European J Pain 2010, 14:97. e1-97.e9.

85. Nijhof SL, Bleijenberg G, Uiterwaal C, Kimpen J: Effectiveness of internetbased cognitive behavioural treatment for adolescents with chronic fatigue syndrome (FITNET): a randomised controlled trial [published online ahead of print March 1, 2012]. Lancet 2012. doi:10.1016/S0140-6736 (12)60025-7.

doi:10.1186/1546-0096-10-15

Cite this article as: Carter and Threlkeld: Psychosocial perspectives in the treatment of pediatric chronic pain. Pediatric Rheumatology 2012 10:15.

\section{Submit your next manuscript to BioMed Central and take full advantage of:}

- Convenient online submission

- Thorough peer review

- No space constraints or color figure charges

- Immediate publication on acceptance

- Inclusion in PubMed, CAS, Scopus and Google Scholar

- Research which is freely available for redistribution

Submit your manuscript at www.biomedcentral.com/submit
C) Biomed Central 